\title{
EL ESTADO SOCIAL 40 AÑOS DESPUÉS: \\ LA DESCONSTITUCIONALIZACIÓN DEL PROGRAMA CONSTITUCIONAL
}

GONZALO MAESTRO BUELGA 
SUMARIO

1. INTRODUCCIÓN 2. EL SIGNIFICADO DE LA CLÁUSULA DE ESTADO SOCIAL EN LA CONSTITUCIÓN ESPAÑOLA DE 1978 3. LA RUPTURA DE LA FORMA ESTADO SOCIAL. 3.1 La reforma del artículo 135 de la Constitución como mecanismo de disolución de las formas de intervención del Estado social. 3.2 La constitución económica europea y la ruptura del Estado social. 3.2.1 La constitución económica comunitaria. 3.2.2 La Unión Económica y Monetaria y la política de la crisis. 3.3 La reforma del mercado de trabajo en España. 4. LA FORMA GLOBAL DE MERCADO Y LA DESCONSTITUCIONALIZACIÓN DEL ESTADO SOCIAL 


\title{
EL ESTADO SOCIAL 40 AÑOS DESPUÉS: LA DESCONSTITUCIONALIZACIÓN DEL PROGRAMA CONSTITUCIONAL
}

\author{
GONZALO MAESTRO BUELGA* \\ Universidad del País Vasco
}

\section{INTRODUCCIÓN}

El Estado social se configura como el núcleo de la crisis de la Constitución y, por ello, del balance de la misma a los casi 40 años de su entrada en vigor. Evidencia los procesos de desconstitucionalización que se producen como consecuencia de la imposición de lo que he denominado la Forma Global de Mercado, como nueva forma que sustituye al Estado social.

Sobre cómo caracterizar la crisis constitucional que afecta a las normas fundamentales inspiradas en el constitucionalismo social, generalmente reconocida, varias son las aproximaciones. En los últimos tiempos ha emergido una fórmula, «desconstitucionalización» ${ }^{1}$, que evidencia la gravedad de la crisis constitucional. La nueva relación establecida entre economía y política, la subordinación de la política a la economía, en la ruptura del Estado social, provoca la desaparición de la Constitución como límite de la política que se

* Catedrático de Derecho Constitucional. Departamento de Derecho Constitucional e Historia del Pensamiento y de los Movimientos Sociales y Políticos. Facultad de Ciencias Sociales y de la Comunicación. Campus de Leioa. Universidad del País Vasco. Barrio Sarriena, s/n. 48940 Leioa (Bizkaia). Email: gonzalo.maestro@ehu.es

1 L. Ferrajoli (2017), «Los espacios y los tiempos de la política y los derechos», en Jueces para la Democracia, n. ${ }^{8} 88$; «Il processo di decostituzionalizzazione del sistema politico italiano», en Ideesocietacivile.it, 15 junio 2010; «Ma l'economia é democratica?», en Lo Straniero, Dic 2012/ ene 2013 , n. ${ }^{\circ} 150 / 151$. 
fortalece en esa nueva posición de tutela directa del proyecto que encarna el capitalismo financiero global: «La omnipotencia de la política demandada por los mercados supone que se agreden los derechos inalienables como el trabajo y el Estado social» ${ }^{2}$. Este proceso de desconstitucionalización se presenta como una fase postconstitucional respecto al constitucionalismo democrático social de la II. ${ }^{a}$ postguerra mundial del pasado siglo, que reduce la Constitución, todavía formalmente vigente, a un papel totalmente marginal ${ }^{3}$. Las transformaciones económicas, sociales y políticas que han conducido a la afirmación de la Forma Global de Mercado han producido una esterilización del constitucionalismo social, trastocando el sistema de fuentes asentado en la afirmación de la jerarquía constitucional que subordinaba al resto del ordenamiento ${ }^{4}$. Desde el punto de vista dogmático puede resultar todavía difícilmente admisible la afectación de la validez constitucional ${ }^{5}$. El intento de distinguir entre validez y normatividad, como forma de recuperar la primera parece un ejercicio de formalismo. Ya Mortati, abordando la cuestión de la distinción entre validez y eficacia y la juridicidad de la constitución material, otorgaba una importancia fundamental a la eficacia ${ }^{6}$, prescindir de esta es, sobre la base de la resistencia constitucional, hacer un ejercicio de voluntarismo formalista ${ }^{7}$, de escisión entre realidad y constitución. Pues, siempre es posible formalmente vincularse a construcciones doctrinales que reclamen la Constitución a pesar de su radical distanciamiento de la forma de Estado en la que se gestó.

La traducción jurídica del proceso de desconstitucionalización es la desnormativización constitucional, la perdida de normatividad en el núcleo de la constitución, específicamente respecto al Estado social y sus materializaciones en el Texto fundamental. Desnormativización como pérdida de la prescriptividad de la norma constitucional, como incapacidad para presidir el ordenamiento y vin-

2 L. Ferrajoli (2012), «Crisi economica e crisi Della democrazia», en Gli asini, 2012, n. ${ }^{\circ} 8$.

3 L. Nivarra, «Non illudiamoci, la costituzione e dietro le apalle», en Uninomade, $14 / 01 / 2013$.

${ }^{4}$ G. LuChenA, «Moti ascensionali Della sovranitá economica», en Amministrazione in camino, 11 octubre 2016.

5 M. Dogliani (2004), «Validitá e normativitá delle costituzioni (a proposito del programa di costituzionlismo.it)», en Costituzionalismo.it, fas.n. ${ }^{\circ} 2$.

${ }^{6}$ C. Mortati (1998), La Costituzione in senso materiale, Giuffré, Milán, pp. 76-92.

G. Maestro Buelga (2010), «La constitución material. Recuperando una propuesta metodológica», en Il diritto fra interpretazione e storia. Liber amicorum in onore di Angelo Antonio Cervati, tomo III, Roma, Aracne Edit, pp. 163 y ss.

7 G. U. Rescigno (2017), «Intorno alle costituzioni, all'economia ed altre questioni collegete», en costitucionalismo.it, fasc 1 . 
cular a los poderes del Estado ${ }^{8}$. Los cambios operados obligan a cuestionarse el sistema de fuentes tal y como se ha construido en el constitucionalismo democrático de la postguerra y de su núcleo: la Constitución ${ }^{9}$.

Para eludir esta ruptura con los paradigmas jurídicos que habían presidido la cultura constitucional europeo se realiza una llamada a la flexibilización a la elasticidad de las construcciones jurídicas que, en tiempos de transición se convierte en componente determinante de las mismas categorías, permitiendo así su supervivencia ${ }^{10}$. Sin embargo, la apelación a la elasticidad constitucional, que permite transformaciones constitucionales radicales sin afectar a la vigencia formal de la norma suprema, usufructuando su potencial legitimador, no debe producir el espejismo de una eficacia constitucional, flexibilizada, por las exigencias de los nuevos tiempos. La elasticidad constitucional no es ilimitada, no permite la esterilización de los principios y prescripciones nucleares de su proyecto. En ese caso, parodiando a Patruno, estaríamos ante un museo a contemplar melancólicamente $^{11}$. Asistimos a una ruptura de la constitución formal producto de la imposición de una nueva constitución material que se afirma en contenidos contrapuestos a los del Estado social y fuerzas hegemónicas distintas que la imponen ${ }^{12}$. La emergencia y afirmación de la Forma Global de Mercado, como nueva forma que se impone sobre la ruptura del Estado social supone el tránsito a una nueva constitución material que se sobrepone a la Constitución formal de 1978, en la medida en que la constitución es fruto de la afirmación de la forma de estado ${ }^{13}$.

Desconstitucionalización de la constitución formal de 1978, como constitución vinculada a la tradición del constitucionalismo social, sustituida por la constitución material que impone la nueva Forma Global de Mercado ${ }^{14}$.

8 A. RugGERI, «Crisi economica e crisi della costituzione». Relazione conclusiva a las V Jornadas italo-hispano-brasileñas «Le costituzione alla prova Della crisi financiaría mondiale», Lecce 14-15 sept. 2012; S. GAMBINO, «Crisi economica e costitizionalismo comtemporaneo», Relazione al congreso «Perspetivas nacionales y supranacionales del derecho constitucional en el contexto de la globalización», Catania, 6 febrero 2015.

9 S. Gambino y W. Nocito, «Crisi dello Stato, governo dell'economia e diritti fondamentali: note costituzionali alla luce Della crisi financiaría in atto», Relazione al seminario «Crisi dello Stato nazionale, governo dell'economia e tutela dei diritti fondamentali», Università di Messina, mayo de 2012.

10 P. Grossi (2012), Introduzione al Novecento giuridico, Laterza, Bari, pp. 33.

11 L. Patruno (2012), «L'elasticitá Della costituzione», en Democrazia e Diritto, 2012, n. ${ }^{\circ} 1-2$, pp. 110 y ss.

12 G. Maestro Buelga, «La Constitución material: recuperando una propuesta metodológica», op. cit.

13 C. Mortati, La Costituzione in senso materiale, op. cit, pp. 182-6.

14 G. Maestro Buelga (2016), «Del Estado social a la Forma Global de Mercado» en Constitucionalismo crítico. Liber amicorum Carlos de Cabo Martin, Tirant lo Blanch, Valencia, pp. 59 y ss. 


\section{EL SIGNIFICADO DE LA CLÁUSULA DE ESTADO SOCIAL EN LA CONSTITUCIÓN ESPAÑOLA DE 1978}

Aunque no debe haber ninguna duda en encuadrar a nuestra Constitución en el constitucionalismo social consolidado en la II. ${ }^{a}$ postguerra mundial, ello no impide realizar algunas consideraciones sobre la recepción del Estado social en el Texto de 1978.

No es un dato intranscendente el momento de elaboración y aprobación, en plena crisis económica, motivada por la crisis energética, que comenzaba a erosionar el arsenal teórico conceptual del keynesianismo y la intervención pública en la economía. Por ello se ha señalado que la praxis política y el desarrollo legislativo han actuado como mecanismo corrector del propio texto constitucional ${ }^{15}$. La doctrina, especialmente la italiana, por su paralelismo con ciertos preceptos constitucionales (arts. 3.2 C. I. y 9.3 C. E.) y la tensión entre los mecanismos de intervención económica y la recepción de la economía de mercado (art. $38 \mathrm{CE}$ ), identificaba elementos de inflexión. ${ }^{16}$. Estos elementos de «transición», peculiares y propios de nuestro Texto fundamental, no empañan la recepción del Estado social en la Constitución, por tanto, la reflexión sobre El Estado social debe partir de la constitucionalización de esta forma de Estado, porque sin ella sería incompresible el conjunto de nuestra Carta: el sistema de derechos y las relaciones económicas.

La base de partida es la el Estado social como forma de Estado. Ciertamente, esta concepción del Estado social y por ello del alcance de la cláusula del artículo 1.1. CE no ha sido compartida por la generalidad de la doctrina constitucional española ${ }^{17}$. Más aún, en la actualidad se sigue considerando a la cláusula de Estado social como una cláusula finalista de escasa densidad jurídica y cuya eficacia depende de la materialización instrumental que realiza el conjunto de ordenamiento jurídico, que no es ajena al momento socio-económico real ${ }^{18}$. Que duda cabe que la sumisión del alcance del artículo 1.1 CE a las exigencias del momento y el traslado a la acción legislativa e infraconstitucional desnaturaliza

15 S. Martin Retortillo (1988), Derecho administrativo económico I, Madrid, La Ley, pp. 39-42.

16 M. Morisi (1984), «Aspectos esenciales de la relación entre Estado y economía en una constitución de la crisis», en La Constitución española de 1978. Estudio sistemático, Madrid, Civitas, pag 377 y ss. F. GALGANO (1978), «Rapporti economico-sociali», en La costituzione spagnola nel trentenale della costituzione italiana, Bolonia, A. ForNi, ed., pp. 87 y ss.

17 Para un análisis del debate sobre sobre el artículo 1.1 de la CE, véase G. MAEstro BuELGA (2002), La constitución del trabajo en el Estado social, Granada, Comares, pp. 137-57.

18 A. Fernandez Miranda (2003), «El Estado social», en REDC, n. ${ }^{\circ}$ 69, pp. 139 y ss. 
el Estado social, posibilitando mantener su aportación legitimadora formal en un contexto de ruptura de la forma de Estado, anulando sus contenidos. Esta concepción permite obviar la desnormativización constitucional que las transformaciones, acaecidas en las últimas tres décadas han producido, sustituyéndola por una concepción infinitamente flexible de la Constitución. Haciéndola metabolizar contenidos imposibles en su génesis ${ }^{19}$.

Para comprender el proceso desconstituyente producido, que esteriliza los instrumentos de materialización de los principios del Estado social, es preciso contraponer una caracterización del mismo con la de la nueva Forma Global de Mercado.

Nuestro acercamiento a la forma de Estado social toma prestada la formulación de Giannini ${ }^{20}$ y su contraposición con el Estado liberal vinculada al conflicto industrial. Estado monoclase, excluyente, frente al Estado pluriclase, integrador de la clase obrera.

La exclusión liberal se articulaba en una doble dirección: política y económica. La política, más presente en la interpretación gianniniana, impedía el acceso de la clase obrera al sistema político (restricciones al sufragio y a la asociación política). La económica consistía en la mercantilización del conflicto social. Confinando el conflicto distributivo al funcionamiento del mercado. La legitimación teórica residía en las formulaciones de la economía clásica, en el pretendido naturalismo del mercado y en sus reglas de funcionamiento que determinan el resultado del intercambio. Este espejismo encubre la radical asimetría de las partes en el intercambio que condiciona la distribución en el mercado. El mercado de trabajo es, sin más, parte del mercado. ${ }^{21}$. La mano invisible, en este caso, no es sino el principio organizativo del mercado que sanciona la asimetría tutelada por el Estado ${ }^{22}$ Por ello, la retribución del trabajo, en la economía clásica, se vincula a las necesidades de subsistencia ${ }^{23}$. La mercantilización del conflicto distributivo, en el marco de la separación de la política y la economía, configuraba el mecanismo de reproducción social que interiorizaba la cons-

19 L. Patruno, L'elasticitá Della costituzione, op. cit.

20 M. S. Giannini (1949), «Rilevanza costituzionale del lavoro», en Rivista Giuridica del Lavoro, pp. 1 y ss.; También «I pubblici poteri negli Stati pluriclase», en Rivista Trimestrale di Diritto Pubblico, 1979, pp. 389 y ss.; y «Stato sociale: una nozione inútile», en Scritti in onore di C. Mortati, vol. I, Giuffré, Milán, 1977, pp. 139 y ss.

21 A. SMith (1979), Investigación sobre la naturaleza y causas de la riqueza de las naciones, Fondo de Cultura Económica, México, pp. 48-9.

22 W. BonEFELD (2013), «Adam Smith and ordoliberalism: on the political form of market liberty», en Review of International Studies, n. 39 , pp. 233 y ss.

23 D. RiCardo (1959), Principios de economía política y tributaria, Fondo de Cultura Económica, Mexico, pp. 71. 
titución económica liberal ${ }^{24}$. Era el mecanismo de exclusión económica fundamental, frente al que reaccionará el Estado social.

El programa del Estado social es el de la integración del trabajo que se manifiesta en forma de compromiso que trastoca la relación entre economía y política, colocando al Estado en el centro de la composición del conflicto distributivo.

Como la exclusión en el Estado liberal, el social articula la integración en la dimensión política y económica. La política se vincula a la subjetivización política del trabajo, a su reconocimiento como sujeto político-social ${ }^{25}$. Esta posición nueva del trabajo forma parte de las reglas de la constitución material del Estado social ${ }^{26}$.

Aunque la integración política del trabajo es inescindible de la económica y precisa de mayores desarrollos, nos detendremos en la integración económica, cuyos mecanismos son considerados, convencionalmente, como el núcleo de esta forma de Estado.

Por nuestra parte hemos diferenciado dos dimensiones de la integración económica: la que se produce a través del mercado y la que lo hace a través del Estado. La primera se vincula a los instrumentos de intervención económica y a la tutela del trabajo (intervención en el mercado de trabajo), la segunda se refiere a los derechos sociales ${ }^{27}$. Aunque la identificación del Estado social con los derechos sociales es también un lugar común, es el mercado, el funcionamiento del sistema económico, el motor principal de la distribución de la riqueza y, por ello, el que constituye el elemento central de la mejora de las condiciones de vida y la integración económica. Los mecanismos de intervención económica permiten que el mercado funcione como forma de integración. El keynesianismo opera como el marco teórico ${ }^{28}$ de acción que permite una intervención de impulso al crecimiento y, a la vez, de redistribución de la riqueza. La ecuación keynesiana es el momento económico de compromiso entre crecimiento y redistribución ${ }^{29}$.

24 M. A. García Herrera (2016), «Estado económico y capitalismo financiarizado: propuestas para un constitucionalismo crítico», en Constitucionalismo crítico. Liber amicorum Carlos de Cabo Martin, Valencia, Tirant lo Blanch, pp. 145 y ss.

25 G. Maestro Buelga, La constitución del trabajo en el Estado social, op. cit., pp. 175-8.

26 P. Barcelona y A. Cantaro (1984), La sinistra e lo Stato sociale, Roma, Ed. Riuniti, pp. 46.

27 G. Maestro Buelga, Del Estado social a la Forma Global de Mercado, op. cit.

28 M. A. García Herrera (1997), «Los antecedentes teóricos del Estado social», en El bienestar en la cultura: Estudios de la Fac de CC. SS. y de la Comunicación en homenaje al prof. Iñaki, Domínguez Vázquez, Universidad del País Vasco, pp. 395 y ss.

29 P. Barcelona y A. Cantaro, La sinistra e lo Stato sociale, op. cit., pp. 43. 
La integración económica a través del mercado se vincula a la constitución económica que, en el Estado social, introduce la primacía de la política en la dirección del mercado ${ }^{30}$, conformando a este como condicionado a la satisfacción de intereses generales. La constitución económica del Estado social establece un vínculo social al mercado ${ }^{31}$. La idea de un mercado condicionado resulta no solo de la intervención económica del Estado, sino de la relativización de los derechos económicos, así se construye un espacio de intercambio que se somete a la decisión política. Aunque como hemos dicho, junto a la intervención económica pública, es la tutela al trabajo, al mercado de trabajo, que se configura como un espacio altamente intervenido, la que permitirá el crecimiento de los salarios y el reparto de la riqueza generada por la intervención económica keynesiana. Los objetivos que expresan el vínculo económico al mercado: pleno empleo y redistribución junto a la intervención normativa promocional del sindicato y la tutela del mercado de trabajo determinan la integración a través del mercado. En la reflexión económica y sociológica el fordismo refleja este funcionamiento del Estado social, esta combinación virtuosa de crecimiento y rentas crecientes ${ }^{32}$. La relación salarial se revela como el elemento nuclear de la teorización regulacionista del fordismo y de su funcionamiento ${ }^{33}$.

La otra dimensión de la integración económica se refiere a los derechos sociales, es decir a una acción distributiva directa como garantía de unos niveles de vida en las situaciones de expulsión del mercado de trabajo. Es, esta forma de integración, complementaria de la primera y cobra sentido en el contexto más general del programa de integración del trabajo en el Estado social, evitando reducir el debate a una cuestión cuantitativa ${ }^{34}$. Sobre la naturaleza de las normas constitucionales sobre los derechos sociales y sobre su estatuto jurídico, el debate parece infinito y los intentos de reforzar su efectividad son una constante en

30 F. GALGANO (1977), «La liberà d'iniziativa economica privata nel sistema delle libertá costituzionali», en La costituzione economica. Trattato di diritto comerciale e di diritto pubblico dell'economia, vol. I, Padua, Cedam, pp. 511 y ss.; A. Predieri (1963), Pianificazione e costituzione, Milan, Ed. Comunitá, pp. 48.

31 G. Maestro Buelga (2002), «Constitución económica e integración europea», en Revista de Derecho Político, n. ${ }^{\circ} 54$, pp. 35 y ss.

32 B. Jessop (1993), «La transizione al postfordismo e il welfare state postkeynesiano», en Stato sociale e mercato. Il welfare state europeo sopravvivera alla globalizzazione dell'economia, MiLA, F. Angeli, pp. 65 y ss.

33 R. Boyer (1986), «Relación salarial, crecimiento y crisis: una relación dialéctica oculta», en La flexibilidad del trabajo en Europa, Madrid, M. de Trabajo, pp. 28 y ss.

34 M. S. Giannini (1977), «Stato sociale: una nozione inútile», en Scritti in onore di C. Mortati, vol I, Giuffré, Milán, pp. 139 y ss. 
el iuslaboralismo y en la doctrina constitucional. Sin embargo la persistencia del debate es también una manifestación de los problemas de su eficacia.

Una manifestación del singular carácter de nuestra Constitución como constitución de transición es precisamente la formulación del artículo 53.3. Este precepto es el punto de llegada de la evolución jurisprudencial y del resultado del debate constitucional, pero también era, en ese momento, una excepción en el constitucionalismo comparado.

Lo cierto es que constitucionalmente, los derechos sociales prestacionales, en sentido estricto, contenidos esencialmente en los principios rectores de la política social y económica (arts. 39-50), configuran un grupo de derechos constitucionalmente minorizados, con una eficacia atenuada. Los intentos doctrinales, parcialmente recibidos por la jurisprudencia constitucional, de reforzar su eficacia no han sido suficientes para superar este estatuto constitucional débil.

Si omitimos la referencia al debate alemán sobre el carácter de la cláusula de Estado social, esta cuestión ha sido evidenciada por la doctrina. La falta de garantías constitucionales del Estado social ${ }^{35}$ supone la configuración constitucional de unos derechos que responden a una lógica distinta del resto de los derechos vinculada con la integración económica.

En la lógica constitucional del Estado social estos derechos incorporan características especiales que explican su debilidad constitucional, aunque en los momentos de esplendor de éste, sus efectos se manifestaban atenuadamente. He establecido cuatro caracteres de los derechos sociales que explican su estatuto constitucional $^{36}$ :

- Son derechos distributivos, esta consideración no afecta a la pretendida distinción entre derechos que cuestan y derechos de libertad ni a la superación de esta distinción por la vinculación de los derechos a la concepción de la libertad positiva, propia del Estado social. La iusfundamentalidad de los derechos sociales no impide reconocer la distinta eficacia de estos ${ }^{37}$. Los derechos sociales distribuyen recursos y actúan en el reparto de la riqueza, insertándose en el circuito redistributivo.

- Como consecuencia de lo anterior, los derechos sociales establecen una relación con el mercado, una relación de compatibilidad, que condiciona su configuración jurídica. Ciertamente, esta compatibilidad no es absoluta, pero se

35 L. Ferrajoli (1982), «Stato social e Stato di diritto», en Politica del Diritto, n. ${ }^{\circ}$ 1, pp. 41 y ss.

${ }^{6}$ G. Maestro Buelga, Del Estado social a la Forma Global de Mercado, op. cit.

37 A. Baldasarre (1997), «Diritti sociali», en Diritti Della persona e valori costituzionali, Turín, Giappichelli, pp. 127 y ss. 
acentúa dependiendo de las exigencias del mercado. Se traduce en distintas formulas, desde la jurisprudencia constitucional alemana: «La reserva de lo posible» ${ }^{38}$, donde la compatibilidad con el mercado se articula, también como colisión con los derechos de libertad económicos «Pero significa que muchas veces los mencionados límites de la capacidad de rendimiento del Estado resultan no solo de los bienes distribuibles existentes, sino esencialmente de aquello que el Estado puede tomar de los propietarios de estos bienes para fines distributivos sin lesionar sus derechos fundamentales» ${ }^{39}$. Hasta la tensión con los nuevos principios presupuestarios, impuestos por la Forma Global de Mercado ${ }^{40}$.

- Los derechos sociales están vinculados al conflicto social. Su grado de satisfacción, su nivel de tutela, es el resultado coyuntural del conflicto ${ }^{41}$. Esta característica, no es sino la consecuencia de las dos anteriores. Esta aproximación significa vincular el principio de la «irregresividad» de los derechos sociales, que ha tenido una cierta receptividad jurisprudencial aunque relativizada, al conflicto, atenuándola fuertemente. La muestra está en nuestra jurisprudencia constitucional «debe entenderse que no se puede privar al trabajador sin razón suficiente para ello de las conquistas sociales ya conseguidas» (STC 81/1982, FJ 3). La evolución jurisprudencial acentúa la disponibilidad política de los derechos sociales anulando la virtualidad de este principio. El punto final lo pone la reforma constitucional del artículo 135 CE que permite introducir en el nivel constitucional un elemento de subordinación radical de los derechos sociales a las exigencias del mercado ${ }^{42}$.

- El resultado es que los derechos sociales en el Estado social son derechos constitucionales débiles.

Se trata, después de las consideraciones realizadas, de aproximarnos a una caracterización de los derechos sociales, que explique su estructura y su estatuto

38 E. BEnda (1996), «El Estado social de derecho», en Manual de derecho constitucional, Madrid, Marcial Pons, pp. 487 y ss.

39 R. Alexy (1993), Teoría de los derechos fundamentales, Madrid, CEC, p. 493.

40 F. Losurdo (2016), Lo Stato sociale condizionato, Turín, Giappichelli.

41 P. Barcellona (1994), «Diritti sociali e Corte costituzionale», en Rivista Giuridica del lavoro e Della Previdenza Sociale, n. ${ }^{\circ} 3$, pp. 325 y ss. También «Crisi dello Stato sociale e strategia dei diritti. Una hipotesi critica», en Le ragioni del diritto. Scritti in onore di L. Mengoni, vol. III, Mila, 1995, Giuffré, pp. 1697 y ss.

42 G. Maestro Buelga (2013), «La constitucionalización del equilibrio presupuestario en la reforma del srt.135 de la Constitución española», en Costituzione econmica e globalizzazione. Liber amicorum in onore di Carlo Amirante, Napoles, Ed. Scientifiche Italiane, pp. 1355 y ss. 
constitucional. Por nuestra parte, nos hemos aproximado a estos derechos afirmando que incorporan una doble dimensión: garantista y conflictual ${ }^{43}$.

La dimensión garantista es expresión de la normatividad constitucional, que se afirma en el constitucionalismo democrático-social de la postguerra, del que necesariamente se deriva la eficacia de los derechos sociales. El reconocimiento de su eficacia constitucional no resuelve el problema, solo impide considerarlas normas sin contenido. Pero, dada la diversa eficacia de las normas constitucionales, su contenido, su alcance, se remite, en su concreción al momento conflictual. El reenvío a la norma infraconstitucional como condición de su eficacia traduce jurídicamente este momento conflictual. La dimensión garantista es una garantía débil, aunque no impide que desde la Constitución se despliegen mecanismos de control que, sin embargo tienen un efecto limitado. Solo adquiere virtualidad junto a la dimensión conflictual, El carácter dual de estos derechos no permite una consideración autónoma de estas dos dimensiones. Entre ellas se establece un equilibrio que funciona, precisamente, en el interior de la forma de Estado social.

A pesar del estatuto constitucional de los derechos sociales, de su debilidad, estos derechos han constituido un importante elemento de integración económica, simbolizando su constitucionalización un nuevo paradigma constitucional. Como se explica la eficacia real de los derechos sociales, pues vinculándolos al resto de los mecanismos que configuran el modelo de Estado social. Por ello, la crítica de Giannini al reduccionismo que evoca la expresión «Estado social» es especialmente pertinente ${ }^{44}$. Los mecanismos de intervención económica, el vínculo social al mercado que introduce la constitución económica del Estado social: pleno empleo y redistribución de la riqueza, junto a la intervención promocional del trabajo, intervención en el mercado de trabajo y promoción sindical y negociación colectiva, configuraban al trabajo como un sujeto fuerte, capaz de codeterminar el resultado del conflicto. El conjunto de intervenciones publicas, establecidas constitucionalmente, permitía un reequilibrio de la posición de los sujetos del conflicto gracias al papel del Estado que actuaba como mediador en la composición del mismo. Es el conjunto de instrumentos que configuran el Estado social el que permite que el resultado de la interrelación entre las dos dimensiones de los derechos sociales funcione. En el marco de este complejo sistema el equilibrio de las dos dimensiones mencionadas se comporta virtuosamente, como mecanismo integrador. La transformación de las bases materiales sobre las que se articulaba esta forma de Estado, supone la esterilización de la

43 G. Maestro Buelga, «Del Estado social a la Forma Global de Mercado», op. cit.

44 M. S. GIANNINI, Stato sociale: una nozione inútile, op. cit. 
constitucionalización de los derechos sociales, su desconstitucionalización fáctica. Por ello hemos afirmado que los derechos sociales, tal y como estaban configurados constitucionalmente, cobraban eficacia en el seno del Estado social. Fuera de este, su relevancia constitucional decae. El reforzamiento paulatino en los treinta años de oro del Estado social es la expresión del equilibrio de las dimensiones garantista y conflictual de estos derechos que permitió una intensificación relativa de la garantía constitucional y una salida al conflicto que fortaleció su contenido.

Los derechos sociales, como el Estado social en su conjunto, se basan en el equilibrio relativo entre las partes del conflicto, que es siempre inestable. Por ello, la afirmación de Carlos de cabo «El estado social siempre estuvo en crisis» ${ }^{45}$ es especialmente pertinente. La cuestión no es la fluctuación del equilibrio, sino su ruptura definitiva: La desaparición del Estado social que compromete la normatividad constitucional radicalmente.

En nuestro Texto constitucional la recepción de la forma de Estado social no se remite solo a la cláusula del artículo 1.1, sino que ésta se manifiesta en tres ámbitos fundamentales, entre otros. Por una parte, la relación que se establece entre poder público y sistema económico (Estado y mercado), la constitución económica. Por otra, los derechos sociales, con los problemas de justiciabilidad que plantea el artículo 53.3 CE. Por último, en el tratamiento de los sujetos del conflicto social, en la subjetivización política del trabajo. Esta se concreta en la constitucionalización de los sindicatos y los partidos políticos, la huelga y la negociación colectiva y en el derecho al trabajo que abre la intervención en este mercado.

La configuración del complejo de relaciones que articulan la forma de Estado social en nuestra Constitución, a pesar de las peculiaridades de su recepción ya señaladas, la insertan en la tradición del constitucionalismo social.

Nuestra jurisprudencia constitucional, sin embargo, no ha extraído las potencialidades que permitía la Carta magna. Aunque realice esa conexión entre los ámbitos antes señalados y su interdependencia en la materialización de la cláusula del artículo 1.1.

La jurisprudencia más relevante, en la aproximación al alcance constitucional del Estado social se produce en los primeros años de actividad del Tribunal constitucional. ${ }^{46}$

45 C. De Cabo Martín (2010), Dialéctica del sujeto, dialéctica de la Constitución, Madrid, Ed. Trotta, p. 88.

46 J. Pérez Royo (1984), «La doctrina del Tribunal constitucional sobre el Estado social», en Revista Española de Derecho Constitucional, n. ${ }^{\circ} 10$, pp. 157 y ss. 
La aproximación más general, aparece en la sentencia 18/1984, en ella se vinculan los derechos sociales, una alusión al pluralismo constitucional vinculable a la subjetivización del trabajo, y la interacción Estado-sociedad, en referencia a la experiencia histórica del mundo occidental en la postguerra. Ciertamente, es una referencia lapidaria y hecha con ocasión del asunto tratado (FJ 3) que no da cuenta de las consecuencias que para el conjunto del ordenamiento debe producir la constitucionalización de esta forma de Estado.

La aproximación jurisprudencial es dúctil y permite atenuar las consecuencias de la cláusula del artículo 1.1 en una pluralidad de significados, vinculados al pluralismo ${ }^{47}$.

Junto a esta sentencia otras dos merecen ser destacadas, la 11/1981 y la 37/1987. La primera, porque construye un modelo de huelga vinculada al Estado social que establece una separación con concepciones ligadas a otras formas de Estado (Estado liberal), señalando su funcionalidad al reconocimiento del conflicto social a al equilibrio de las partes en el mismo, fortaleciendo los instrumentos de autotutela del Trabajo. Esta sentencia debe ser puesta en relación con la 22/1981, sobre el derecho al trabajo que, a pesar de su debilidad legitima una intervención en este mercado. La segunda, porque establece una relación entre poder público, intereses generales y derechos económicos que permiten insertar la relación público privado en la lógica de la constitución económica del Estado social. Quizás la construcción más lograda sobre la influencia del Estado social sobre la propiedad y los derechos económicos.

Las demás referencias al estado social son implícitas y se realizan en el contexto de la jurisprudencia sobre la igualdad y el artículo $9.2^{48}$.

La muy sucinta referencia a la primera jurisprudencia del Tribunal constitucional es suficiente para constatar como se ha realizado la interiorización de las consecuencias de la constitucionalización del Estado social. Pero tan revelador como esta es el abandono del Estado social en la argumentación constitucional por parte del Tribunal y la práctica irrelevancia de éste como parámetro de constitucionalidad que presida el ordenamiento jurídico en el último periodo ${ }^{49}$. La culminación de este proceso viene dada por la STC 119/2914 sobre la reforma laboral que opera una inversión y la esterilización de los efectos de la cláusula

47 M. A. Aparicio Perez (1993), «El Estado social en la jurisprudencia del Tribunal constitucional», en Estudios sobre el Estado social. Estado social y la Comunidad autónoma de Andalucía, Madrid, Tecnos, pp. 47 y ss.

48 E. Carmona Cuenca (1994), «El principio de igualdad material en la jurisprudencia del Tribunal constitucional», en Revista de Estudios Políticos, n. ${ }^{\circ} 84$, pp. 265 y ss.

49 M. A. García Herrera, Estado económico y capitalismo financiarizado: propuestas para un constitucionalismo crítico, op. cit. 
del artículo 1.1 convirtiendo en irrelevante. Junto a esta nueva jurisprudencia que revela la capacidad disciplinante de la constitución material de la Forma global de mercado, la reforma constitucional del artículo 135 opera una inversión de la relación entre preceptos constitucionales, fruto de la contradicción entre las lógicas que incorporan, desplazando al Estado social a una posición irrelevante. El punto de llegada de nuestra evolución constitucional es la práctica desconstitucionalización de la forma de Estado social.

Fijada la caracterización del Estado social y la recepción constitucional de esta forma de Estado queda por ver la evolución tanto del Texto constitucional como de la normativa legal que dará cuenta de los nuevos contenidos que contrastan con aquellos que han definido, a pesar de variantes normativas que registra el derecho comparado, a la forma Estado social. Estas se corresponderán con los que identifican a la nueva forma emergente que hemos denominado Forma Global de mercado.

Se trata de ver las novedades en las tres dimensiones: constitución económica, derechos sociales y subjetivización política del trabajo e intervención en este mercado, elementos, como se ha dicho conexos a la integración constitucional del conflicto. Pues es este el elemento que define a la nueva forma: la expulsión del conflicto del sistema político y, por ende de la constitución, fruto de la exclusión del trabajo. Exclusión frente a integración en el Estado social.

\section{LA RUPTURA DE LA FORMA ESTADO SOCIAL.}

Como hemos señalado, la ruptura del Estado social y por ello, la desnormativización constitucional que conlleva, se ha producido en la vigencia formal del texto de 1978 al igual que en nuestro contexto europeo. Ciertamente episodios importantes que afectan al Estado social y a sus contenidos constitucionales se han producido,: la reforma del artículo 135 es sin duda determinante. Pero más allá de esta, aparentemente la Constitución continúa recogiendo los contenidos que permitían identificar al Estado social. La transcendencia de la reforma del artículo 135 debe vincularse al contexto en que se produce: la política de la UE en la crisis y las medidas de disciplina reforzada que introduce ${ }^{50}$. Porque son estas las que erosionan los contenidos constitucionales e introducen una tensión insuperable en el propio Texto constitucional y sus principios fundamentales ${ }^{51}$.

50 F. Bilancia (2014), «Spending review e pareggio di Bilancio. Cosa rimane dell'autonomia locale», en $R E A F$, n. 2 , pp. 60 y ss.

51 G. BuCCI, «BCE versus costituzione italiana», en Sinistrainrete, 25 de junio 2012; G. GRAsso, «Le parole Della costituzione e la crisi economico-finanziaria», en Osservatorio costituzionale AIC, 4 febrero 2016. 
Es el ordenamiento europeo el que esta produciendo normativamente la erosión constitucional y operando, jurídicamente, este proceso de desconstitucionalización del constitucionalismo social.

La absorción de las constituciones de los Estados miembros y su correlativa erosión se ha pretendido resolver dogmáticamente mediante la introducción de nuevas categorías que debieran servir para repensar la propia concepción de la constitución. El constitucionalismo multinivel ${ }^{52}$, de indudable éxito en la doctrina, ha pretendido mediante el expediente de la integración normativa de textos fundamentales y su inevitable interrelación, podríamos decir, por elevación, superar la contradicción entre ordenamientos que resultaba insuperable.

El problema del constitucionalismo multinivel no es solo la tensión entre realidad y la instrumentalización de los criterios de relación interna de los niveles europeo y estatal, sino que la propia construcción no resiste la convivencia normativa que se pretende afirmar. En realidad, el constitucionalismo multinivel, solo es posible como forma de integración constitucional si los distintos niveles son compatibles. Sobre la base, poco discutible, de la contradicción entre los ordenamientos constitucionales de los Estados miembros pertenecientes a la tradición del constitucionalismo social y los Tratados solo es posible la absorción de las constituciones estatales desnormativizándolas. Predicar unas relaciones entre los niveles constitucionales (interordinamentales), no mediadas por el principio de jerarquía, lleva a entender que son posibles lógicas diversas en éstos, en ausencia de una unidad interna, que dote de coherencia ordinamental a la estructura supraestatal multinivel. Esta interpretación es insostenible, como muestra la realidad, pues el proyecto de la Unión es absorbente y disciplinante, sometiendo, con lógica jerárquica, a los distintos niveles al proyecto que incorpora la UE.

\subsection{La reforma del artículo 135 de la constitución como mecanismo de disolución de las formas de intervención propias del estado social}

Visto que los elementos fundamentales que inciden en este proceso de desconstitucionalización del Estado social, son la integración europea y la reforma

52 I. PERNICE (1999), «Multilevel constitucionalism and the trety of Amsterdam; European constitution-making revisited?", en Common Market Law Review, n. ${ }^{\circ} 36$, pp. 703-50; (2000) «De la Constitution composée de L'Europe», en Revue Trimestielle de Droit Européenne, n. ${ }^{\circ} 36$, pp. 623-647; (2002), «Multilevel Constitutionalism in the European Union», en European Law Review, n. ${ }^{\circ} 27$, pp. 511-29; Más recientemente «La dimensión global del constitucionalismo multinivel. Una respuesta legal a los desafíos de la globalización» en $C E U$, serie Unión europea y relaciones internacionales, n. ${ }^{\circ} 61 / 2012$. 
constitucional como introducción en el seno del Texto fundamental de principios contradictorios con la forma de Estado que consagra la constitución, impulsada desde la UE, la atención prioritaria debe fijarse en estos elementos. La evolución normativa infraconstitucional, efecto de los dos anteriores, dará cuenta de cómo metaboliza el ordenamiento estatal los principios de la nueva Forma Global de Mercado.

Que la constitucionalización del equilibrio presupuestario supone la introducción en el Texto un nuevo principio capaz de condicionar las decisiones fundamentales de la Constitución y, especialmente los derechos sociales resulta evidente. La constitución financiera expresa una fuerza condicionadora capaz de incidir en la forma de Estado y en los derechos ${ }^{53}$. Sin embargo este vínculo fuerte que opera desnaturalizando la constitucionalización del Estado social es banalizada por nuestra propia jurisprudencia constitucional en contraste con otras.

Nuestra Tribunal constitucional, tercia en el debate doctrinal sobre la reforma del artículo $135 \mathrm{CE}$, desestimando el recurso de amparo presentado contra las decisiones del Congreso respecto al procedimiento de tramitación de ésta, con una aproximación burdamente formalista que descarta de relación con el artículo 1.1 CE (auto TC 9/2012). Se vincula a la primacía del principio de estabilidad presupuestaria y al ordenamiento europeo, presente en su jurisprudencia (STC 134/2011, 157/2011 y 196/2011 entre otras). Esta concepción, expresada palmariamente se encuentra en intervenciones de exmiembros del Tribunal, que establecen una relación de dependencia acusada entre los principios de Estado social y la estabilidad presupuestaria. Éste se configura como un límite que determina el verdadero alcance del artículo 1.1. La estabilidad presupuestaria, máxime después de la reforma del artículo $135 \mathrm{CE}$, se convierte en un parámetro de constitucionalidad fuerte ${ }^{54}$ capaz de determinar los contenidos de los derechos sociales.

Nuestro Tribunal constitucional se distancia de la posición de otros que, sin comprometer la influencia determinante de la estabilidad presupuestaria en los derechos sociales, imponen un atemperamiento de esta, dotando de cierta virtualidad a los contenidos constitucionales expresión del Estado social, en orden a limitar el contenido absolutamente expansivo y determinante de la constitu-

53 F. SAITTO (2017), «Costituzione finanziaria» ed effettività dei diritti sociali nel passaggio dallo «Stato fiscale» allo «Stato debitore», en Rivista AIC, n. ${ }^{\circ} 1$.

54 A. Rodríguez Bereijo (2013), «La reforma constitucional del artículo 135 CE y la crisis financiera del Estado», en Instituto de Estudios Fiscales. M. ${ }^{\circ}$ de Hacienda y AA. PP, Crónica presupuestaria, n. ${ }^{\circ} 1$, pp. 5 y ss. 
ción financiera ${ }^{55}$. El ordenamiento de la Unión ha elevado la estabilidad presupuestaria a principio fundamental, en el vértice de éste, como instrumento de salvaguardia del proyecto de integración europea diseñado desde el tratado de Maastricht, imponiendo su constitucionalización entre los Estados. Éste opera produciendo, ahora en el interior de sus propios ordenamientos constitucionales una distorsión radical de su forma de Estado ${ }^{56}$. El equilibrio presupuestario actúa, en el contexto de la competencia interestatal, en los sistemas tributarios y en la desaparición del vínculo social al mercado que introducía el Estado social. En este marco, este principio opera sustancialmente comprimiendo el gasto social, debilitando la base económica sobre la que se basaba su eficacia. De esta forma se establece la contradicción entre el nuevo artículo 135 y el artículo 1.1. $\mathrm{CE}$, máxime en los términos radicales en los que se recoge en nuestra reforma constitucional. La constitucionalización del equilibrio presupuestario radicaliza el carácter de derechos condicionados de los derechos sociales ${ }^{57}$, rompiendo el equilibrio entre la dimensión garantista y la conflictual de estos derechos. Ahora, con las novedades normativo-constitucionales, se revela la fragilidad de la construcción jurídica de los derechos sociales y las condiciones de su funcionamiento. La constitucionalización del reequilibrio de los sujetos del conflicto era la condición para el funcionamiento de los derechos sociales, dada la debilidad de su dimensión garantista. Por ello, el contexto en el que actúa la estabilidad presupuestaria, acentúa la dimensión conflictual de éstos, en un modelo que expulsa al trabajo, remercantilizando el conflicto, y provoca la desconstitucionalización de los derechos sociales. La escasa resistencia jurisprudencial no supone una barrera de defensa del Estado social. Es una posición marginal, que solo juega en situaciones límite, colocándolo en posición de excepción frente a la regla monetarista y sus efectos disolventes respecto a los fundamentos constitucionales.

Lo especialmente significativo de la reforma constitucional es que, introduciendo la contradicción en el seno de la propia constitución, disuelve formalmente los principios constitucionales impidiendo la resistencia frente al ordenamiento de la Unión y debilitando las líneas de autoprotección trazadas por algunas jurisprudencias constitucionales. El pretendido dialogo entre cortes ${ }^{58}$ como

55 M. Nogueira de Brito (2013), «La jurisprudencia de la crisis del Tribunal constitucional portugués», en Teoría y Realidad Constitucional, n. ${ }^{\circ} 38$, pp. 575 y ss.; F. SAITTO, «Costituzione finanziaria» ed effettività dei diritti sociali nel passaggio dallo «Stato fiscale» allo «Stato debitore», op. cit.

56 F. Losurdo, Lo Stato sociale condizionato, op. cit, pp. 6-8.

57 F. Losurdo, Lo Stato sociale condizionato, op. cit, pp. 156

58 M. LuCIANI (2012), «Conclusioni» a Il diritto costituzionale alla prova Della crisi economica, Napoles, Jovene, pp. 572. 
eufemismo de la subordinación de las jurisprudencias estatales al TJUE se revela ahora como forma absorción de estas al igual que normativamente se había producido en el proceso de integración europea post Maastricht. La admisión, ya normalizada en algunas jurisdicciones constitucionales, incluida la nuestra ${ }^{59}$, de la cuestión prejudicial muta la relación y autonomía de los Tribunales en la perspectiva señalada.

\subsection{La constitución económica europea y la ruptura del Estado social}

\subsubsection{La constitución económica comunitaria}

El segundo elemento que pone en crisis el paradigma constitucional surgido en la postguerra mundial es la integración europea. Esta se conforma como el mecanismo normativo de desconstitucionalización del Estado social.

La construcción de los caracteres del ordenamiento comunitario tenían la doble función de afirmar la autonomía de este frente a los Estados miembros y evitar la influencia del constitucionalismo social en el ordenamiento europeo. Tanto la primacía del ordenamiento de la Unión, como la construcción jurisprudencial del sistema de derechos que, hasta los años setenta constituyó el núcleo de la conflictiva relación entre ordenamientos, tenían claramente esa finalidad.

Desde el inicio de la construcción europea ésta se configuró como un proyecto en contradicción con el Estado social y los contenidos que le caracterizaban. La CEE cuyo elemento central se articula en torno al modelo de la economía de mercado que se define como un mercado incondicionado, refractario a la intervención publica, legitimada por la introducción constitucional del vínculo social al mercado. El modelo de evidente y reconocida inspiración ordoliberal ${ }^{60}$, aunque interpretado de forma más acentuadamente liberal ${ }^{61}$ que contradice el modelo de economía mixta y de la dirección política de la economía.

Estos dos modelos contradictorios, sin embargo, funcionaron coexistiendo entre si. La convivencia se organizó en base al principio: «Keynes en casa y Smith

59 M. Cartabia (2008), «La Corte Costituzionale e la Corte di Giustizia: atto primo», en Giurisprudenza Costituzionale, pp. 1288 y ss.; D. Basili, «Corte Costituzionale, rinvio pregiudiziale alla Corte di Giustizia UE e dialogo tra le Corti: Evoluzione e prospettive», en Federalismi.it, octubre 2011; A. Aguilar Calahorro (2011), «La primera cuestión prejudicial planteada por el Tribunal Constitucional ante el TJUE-Auto del TC 8/2011 de 9 de junio», REDCE, n. ${ }^{\circ} 16$.

${ }^{60}$ M. E. Streit y W. Mussler (1995), «The economic constitution of the European Community: form Rome to Maastricht», en European Law Journal, n. ${ }^{\circ} 1$, pp. 5 y ss.

61 F. Caronna (2001), «Qualque spunto sull'evoluzione Della costituzione economica dell'Unione Europea», en Ars interpretandi, n. ${ }^{\circ}$ 6, pp. 271 y ss. 
fuera». La construcción del mercado común se organizaba con los principios ordoliberales y en los Estados se afirmaba una economía mixta de dirección pública. Este reparto de espacios era posible porque el mercado común se construía mediante unas reglas de relación entre Estados con autonomía económica. Esta coexistencia estaba llamada desaparecer, era insostenible, precisamente por sustentarse en principios contradictorios. La superación de la contradicción significaba la imposición de la constitución económica europea y la absorción en esta de la de los Estados miembros. El momento de inflexión se sitúa en la construcción de la Unión Económica y Monetaria, con el Tratado de Maastricht ${ }^{62}$. En realidad La UEM era la respuesta a la crisis del modelo fordista, a la tensión entre mercado y redistribución que el conflicto social había producido a comienzo de los años setenta. Coincide, también, con el comienzo de la globalización financiera y el desmontaje del control de la circulación de capitales. Fin de Bretton Woods como marco global en el que se reordenan las relaciones económicas ${ }^{63}$ que es el contexto donde se inserta la integración europea post-Maastricht.

La constitución económica de la CEE. Como hemos señalado la relación entre las constituciones económicas de la Comunidad y los Estados miembros estaba presidida por una división de espacios ${ }^{64}$, aunque por la propia lógica de la integración comunitaria el mercado común tenía una fuerza expansiva que acabaría afectando al constitucionalismo social estatal. La plena instauración del mercado común era, en la previsión de los Tratados, gradual con un periodo de transición de 12 años, que se fue prologando. Por ello, la tensión entre las constituciones económicas y la preeminencia de la comunitaria se expresa en los momentos de la crisis del Estado social.

La constitución económica comunitaria se construye sobre tres pilares: Las libertades económicas básicas del Tratado, la disciplina de la competencia y los mecanismos de limitadores de la intervención publica económica: especialmente de las ayudas estatales ${ }^{65}$. El primer eje lo constituyen los instrumentos jurídicos de la conformación del mercado y proclama, por ello la centralidad del mismo en la constitución económica. El segundo, introduce un mecanismo que afecta a la intervención económica estatal porque expulsa a cualquier forma de

62 A. Somma, »Un quarto di secolo con Maastricht: liberiamocene, o fascismo», en Micromega, online, 4 febrero 2017.

63 A. BagnaI (2011), «Crisi financiaria e governo dell'economia», en Costituzionalismo.it, fasc. 3 .

${ }^{64}$ C. Joerges (2005), «Que reste-t-il de la constitution economique européenne aprés la constitutionalisation de l'Europe. Une rétrospective mélancolique», en Les cabiers européens de sciences politiques, $\mathrm{n} .{ }^{\circ} 9$

65 S. CASSESE (1995), La nuova costituzione economica, Bari, Laterza, pp. 31-2. 
condicionamiento del principio básico de funcionamiento del mercado. El tercero es una manifestación del segundo, pero que incide directamente en las relaciones establecidas entre Estado y economía en el Estado social. Todos ellos conforman una relación mercado-poder público que expulsa el vínculo social al sistema económico en el funcionamiento del Mercado común. Éste era un espacio reservado a los Estados. El mercado común es el instrumento para la satisfacción de los objetivos de la Comunidad y al que los Tratados asocian también la mejora de las condiciones de vida. De esta forma, es el mercado el espacio de distribución operando la mercantilización del conflicto social, su expulsión, frente a la integración del constitucionalismo social.

La configuración de los derechos económicos es sustancialmente distinta de la del Estado social. Son derechos fuertes, correspondientes a un mercado incondicionado. Los derechos económicos, entre ellos la propiedad, eran en el constitucionalismo social derechos relativos, su estructura se vinculaba a la intervención pública económica y al vínculo social al mercado. En la constitución económica comunitaria la propiedad no es un derecho relativo en el sentido expresado, es un derecho central ${ }^{66}$. La propiedad condiciona la relación economía-Estado y la intervención pública. La especificación del Tratado de Roma, que se repetirá en las sucesivas reformas, contenida en el artículo 222 «los Tratados no prejuzgan el régimen de propiedad de los Estados miembros» resulta esterilizada por las normas de la competencia que imponen un funcionamiento de la empresa pública equivalente a un sujeto privado en el mercado. Es la inversión de la concepción propietaria del Estado social. El precepto citado, como ha señalado la doctrina, trae su origen en la declaración Schuman de mayo de 1950 y pretendía evitar los problemas de la nacionalización de empresas y el papel del sector público en los momentos de la postguerra ${ }^{67}$, pero resultaba corregido por la lógica del Tratado.

EL Tratado de Roma, como hemos señalado, sienta las bases jurídicas y políticas para una esterilización de los mecanismos de intervención económica del Estado social.

Una última observación sobre el proceso de integración europea pre-Maastricht, ésta referida a los derecho sociales. Como se sabe el Tratado de Roma ignora los derechos, y la jurisprudencia del TJCE en el prolongado proceso de

66 M. Comporti (2008), «La propietá europea e la propietá italiana», en Riv. Dir. Civ., I, pp. 192 y ss.

${ }^{67}$ L. NivarRa, «La propietá europea tra controriforma e rivoluzione passiva», congreso «Diritto civile e principi costituzionali europei e italiani», Fac di Giurisprudenza Perugia, 25 de marzo 1011; D. Vignes (1970), artículo 222, Le droit de la Communauté économique européenne: comentaire du traité et des textes pris pour son application, vol. 15, P. U. De Bruxelles, pp. 412 y ss. 
reconocimiento de los derechos margina a los derechos sociales. La base de partida era la mercantilización del conflicto que consideraba al mercado como el espacio de distribución. El desequilibrio entre libertades económicas y derechos sociales era evidente ${ }^{68}$. La construcción del mercado común y su lógica expulsa la lógica redistribuidora que inevitablemente afecta a su funcionamiento. Solo resulta ocultada por la separación de espacios y la autonomía económica de los Estados $^{69}$. Los primeros Tratados presuponían el constitucionalismo social de los Estados miembros, pero establecía una relación contradictoria con el, en materia de derechos sociales esto se manifestaba excluyéndolos de los mismos, excluyendo los mecanismo que el constitucionalismo social había ideado para su reconocimiento $^{70}$. El reparto de espacios no es sino el discurso que encubre la concepción comunitaria del mercado que impide la afirmación de estos derechos. El mercado como principio irrevocable del ordenamiento comunitario ${ }^{71}$ dificulta el reconocimiento de los derechos sociales porque éstos afectan al mercado. El vínculo económico de la constitución económica comunitaria ${ }^{72}$ establece la contradicción entre mercado y derechos sociales.

\subsubsection{La UEM y la política de la crisis}

La Unión Económica y Monetaria, en algunas opiniones, suponía el fin de la constitución económica establecida por el Tratado de Roma, la trasgresión de los principios ordoliberales, tanto por la recepción de cierta dimensión social en el proceso de integración, como por los mecanismos interventores en política económica y estabilidad financiera. Libertad y competencia entran en contradicción, para estos autores con los nuevos principios establecidos desde Maastricht en adelante ${ }^{73}$. Sin embargo, difícilmente puede sostenerse esta ruptura. La con-

68 M. Poiares Maduro (2001), «L'equilibre insaissible entre la liberté économique et les droits sociaux dans l'Union Européenne», en L'union Européenne et les droits de l'bomme, Bruselas, Bruylant, pp. 465 y ss.

69 S. Giubboni, Diritti social e mercato. La dimensione sociales dell'integrazione europea, Bolonia, il Mulino.

70 A. Baldasarre (2003), «La tutela comunitaria dei diritti dell'uomo e la carta costituzionale italiana», en Enunciazione e giustiziabilitá dei diritti fondamentali nelle Carte costituzionali europei, Milan, Giuffré, 1994, pp. 79 y ss.

${ }^{71}$ G. GuARINo (1992), «Pubblico e privato nella economia. La sovranitá tra costituzione ed istituzoni communitarie», en Quaderni Costituzionali, n. ${ }^{\circ} 1$, pp. 21 y ss.

72 G. Maestro Buelga (2000), «Constitución económica y derechos sociales en la Unión europea», en Revista de Derecho Comunitario Europeo, n. ${ }^{\circ} 7$, pp. 123 y ss.

73 M. E. STREiT y W. Mussler, «The economic constitution of the European Community: form Rome to Maastricht», op. cit.; W. Sauter (1998), «The economic constitution of the European 
tinuidad con la CEE y su constitución económica no solo se evidencia con la presencia de la configuración del mercado y la continuidad de la tutela de la competencia, sino que los elementos sociales introducidos, más presentes desde la reforma de Amsterdam, son subalternos y persisten en el modelo de integración negativa. La emergencia de la literatura sobre el llamado «modelo social europeo» ${ }^{74}$ no empaña la afirmación de que este, en la forma en se recoge en los Tratados, representa un mecanismo europeo de construcción regresiva ${ }^{75}$. Igualmente, las nuevas competencias de la Unión que incorpora la UEM con la introducción de mecanismos de control macroeconómico-financiero, se insertan en la lógica de tutela del mercado en las nuevas condiciones de la competencia global. Expresan también una continuidad con el modelo que permite establecer un vínculo entre la revisión neoliberal de la concepción del mercado (ordoliberalismo), el consenso de Washinton, la globalización y las políticas de la crisis de la Unión. Neoliberalismo como nexo de unión que pretende, desde sus inicios, la imposición de un nuevo paradigma indiscutible y la extensión de sus principios al conjunto de la sociedad, como criterio de relación social ${ }^{76}$.

Ciertamente, las sucesivas reformas de los Tratados que instauran y desarrollan la UEM se sitúan en la lógica de continuidad con los Tratados fundadores de la CEE, aunque introducen una novedad trascendental, la organización del fin de la autonomía económica de los Estados, cerrando así la contradicción entre los ordenamientos que en el periodo en que actuaba el principio de la separación de espacios, parecía presidir la relación entre la Comunidad y los Estados.

Los efectos de la UEM fueron la absorción de las constituciones económicas de los Estados por la de la Unión, con la consiguiente expulsión normativa de los principios del constitucionalismo social. El fin de la autonomía económica de los Estados sanciona, normativamente, el fin de constitucionalismo social, no es de extrañar que la emergencia de estas concepciones de la constitución, la más reseñable la del multinivel, se produzca en estos momentos.

Los mecanismos de control financiero-presupuestario y de coordinación macroeconómica producen estos efectos. De esta forma la UEM lo que hace es

Union», en Columbia Journal of European Law, n. ${ }^{4}$, pp. 27 y ss.; C. JoERGES (2005), «Qué tiene de social-demócrata la constitución económica europea», en $R E D C$, n. ${ }^{\circ} 73$, pp. 9 y ss.

${ }^{74}$ G. Maestro Buelga (2008), «La inaprehensible ciudadanía social europea», en Revista de Derecho Político, n. ${ }^{\circ} 71-72$, pp. 747 y ss.

75 G. Bucci y L. Patruno (2005), «Riflessioni sul c.d. modello sociale europeo, sull'Europa "sociale" dei capi di governo e sul mutato rapporto tra costituzione ed economia», en Costituzionalismo.it, fasc. 3 .

76 P. Dardot y C. Laval (2013), La nuova racione del mondo. Critica Della racionalità libelista. Roma, Derive Approdi, pp. 5-8. 
extremar la lógica presente en los Tratados fundacionales, cerrando el círculo y la contradicción normativa anterior.

El diseño que la UEM incorpora ha sido criticado y considerado como el origen de la crisis del euro y la especial gravedad de los efectos de la crisis financiera en la UE con la deuda soberana. La crítica se concentra en la asimetría entre los mecanismos de control y los de gobierno económico, en manos de los Estados, ligados a la política económica ${ }^{77}$. Esta consideración me parece equivocada. No hay un error de diseño en el Pacto de Estabilidad y Crecimiento y en el reparto competencial de las políticas económicas. La decisión estratégica es acentuar los mecanismos disciplinarios que se convierten en la forma fundamental de dirección económica. La dialéctica control fuerte y gobierno débil ${ }^{78}$ que preside la construcción de la gobernaza económica europea, entra dentro de la lógica de la autonomización de la economía y su despolitización. Los mecanismos de control se autonomizan, sobre todo en los instrumentos usados en la crisis, basados en criterios de asepsia política y presididos por una política monetaria autónoma del BCE. La política económica, sin embargo, también está sujeta a mecanismos de control. En el contexto de la coordinación de las políticas económicas, mediante las orientaciones generales, concebidas como instrumento de controlmonitorización, que determina la lógica de la relación en el interior del Estado y fija las prioridades de la intervención. Estas se concretan en la llamada recurrente a las reformas estructurales como contenido fundamental de la política económica. La tutela, aparentemente débil, de las políticas económicas se refuerzan con el control presupuestario y financiero.

Los resultados de las políticas de austeridad, fruto del control fuerte de la gobernanza económica europea, son efectos queridos que acentúan el carácter disciplinante de la política de la crisis. Lo muestra la persistencia de los mismos durante este periodo. Ciertamente, se pueden introducir mecanismos de atenuación de los efectos de la austeridad, pero en sustancia el resultado es valorado positivamente por las instituciones de la Unión. Las propuestas de la Comisión para la profundización de la UEM así lo indican. Éstas, genéricamente formuladas, son de una corrección limitada (Documento de reflexión sobre la profundización de la Unión Económica y Monetaria, COM (2017) 91, de 31 de mayo) que pretenden apuntalar un sistema que ha acreditado su insostenibilidad social. Por otra parte, las medidas adoptadas al calor de las crisis (Euro plus, six pack, fiscal compact y el MEEF) acentúan los efectos mencionados. Junto con las medi-

77 F. Losurdo, Lo Stato sociale condizionato, op. cit, pp. 31.

78 G. Maestro Buelga (2007), «Pacto de estabilidad y gobierno económico en la Unión Europea», en Diritto, politica ed economia dell'unione, Turin, Giappichelli, pp. 17 y ss. 
das de austeridad, fruto del equilibrio presupuestario, estas medidas incorporan una presión respecto a las «reformas estructurales», que fijan normativamente el proyecto radical que incorpora la UE. El TJUE ha contribuido a consolidar la presión para imponer las reformas, consolidando su jurisprudencia en materia de cláusulas sociales en la contratación pública ${ }^{79}$.

No es posible un análisis detallado de la normativa post-Maastrich y la adoptada en la crisis, vasta señalar los efectos de éstas en el orden constitucional de los Estados miembros.

Sobre los efectos en los derechos sociales de la austeridad impuesta ya han sido señalados y generalmente reconocidos, aunque conviene señalar los efectos en el mercado de trabajo, como consecuencia de las reformas estructurales ${ }^{80}$. En nuestro caso el más relevante ha sido la reforma del mercado de trabajo. La realidad de los efectos de la austeridad excusa de un comentario respecto a la novedad que incorpora el Tratado de Lisboa: la carta de derechos Fundamentales de la Unión Europea. Las expectativas que había provocado esta novedad, fundamentadas en la indivisibilidad de los derechos que incorporaba, ha sido desmentida y se ha pasado a un escepticismo sobre la virtualidad de este mecanismo ${ }^{81}$.

Una última consideración sobre la aplicación de las ayudas previstas en el Mecanismo Europeo de Estabilidad Financiera. La condicionalidad estricta al cumplimiento de los ajustes económicos y las reformas estructurales ha producido una suerte de vínculo normativo general a los Estados asistidos, que se configura como criterio de constitución material europeo, de los principios establecidos en los años noventa por el FMI del pasado siglo (Consenso de Washintong). El mecanismo del MEEF esta constituido a imagen de aquel y, de igual forma, los ajustes estructurales se conciben como una reestructuración normativa de largo alcance que afecta a los contenidos constitucionales del Estado social ${ }^{82}$.

En definitiva, el ordenamiento europeo, los Tratados y la legislación de la crisis, actúan como mecanismo normativo de desconstitucionalización del Esta-

79 C. Joerges y S. Giubboni (2013), «Diritto e política nella crisi europea», en Riv. Critica Dir. Privato, n. ${ }^{\circ} 3$, pp. 343 y ss.

${ }^{80} \mathrm{G}$. Fontana, «Crisi económica ed effettività dei diritti social in Europa», Forum costituzionale.it, 27 nov, 2013; A. BAYlos y F. Trillo PÁrraga (2013), «El impacto de las medidas anticrisis y la situación social y laboral en España», Estudio del CES europeo.

${ }^{81}$ S. Giubboni (2013), «Cittadinanza, lavoro e diritti sociali nella crisi europea», en Rivista del diritto Della sicurezza sociale, n. ${ }^{\circ}$ 3, pp. 491 y ss.

${ }^{82}$ M. Giannelli (2013), «La "condizionalità" democrática dell'Unione europea e la sua applicabilità alle istituzioni finanziarie internazionali», en Studi sull'integrazione europea, n. ${ }^{\circ} 3$, pp. 327 y ss. 
do social, de sus contenidos tanto de gobierno económico, como del vínculo social y del sistema prestacional.

\subsection{La reforma del mercado de trabajo en España}

Singularizar la reforma del mercado de trabajo en el proceso de desconstitucionalización de Estado social se explica en relación con la caracterización del Estado social que hemos, muy sucintamente, realizado. La intervención en el mercado de trabajo determinaba el funcionamiento del mercado en el contexto del vínculo social al mercado que establecía el constitucionalismo social. El suelo de predeterminación de los condiciones de trabajo, la negociación colectiva, la individualización de ésta y debilitación de los derechos de conflicto social ${ }^{83}$ tienen por finalidad remercantilzar el conflicto distributivo, alejándolo del programa integrador del Estado social. El último episodio de la reforma del mercado de trabajo viene representado por la ley 3/2012 de medidas urgentes para la reforma del mercado laboral. Procede solo reseñar las aportaciones de la última reforma respecto a la intervención normativa, en este ámbito, del constitucionalismo social. Se ha señalado que el objetivo, verdadero hilo conductor de la reforma, es la devaluación salarial. Reducir los salarios mediante diversas técnicas que establecen un sistema de presiones es el efecto de esta reforma ${ }^{84}$. Los mecanismos podríamos clasificar en tres apartados: los que afectan a la negociación colectiva, la intensificación de la flexibilidad externa, despidos, y la flexibilidad interna.

El primero afecta directamente al instrumento que permitió un comportamiento del mercado que fortalecía la capacidad de negociación del trabajo, favoreciendo su integración económica. La preferencia absoluta del convenio de empresa, opera reduciendo la cobertura de trabajadores con protección, especialmente de los más débiles. La reforma de la ultraactividad de los convenios debilita la negociación inutilizándola como forma de mantenimiento de los niveles salariales y de condiciones de trabajo. La inaplicación de los convenios, ahora ampliamente facilitada, erosiona la capacidad negociadora sindical de forma

83 G. Maestro Buelga (2013), «Derechos de conflicto social y participación política en la Unión europea», en Crisis de la democracia y nuevas formas de participación, Valencia, Tirant lo Blanch, pp. 151 y ss.

84 J. Cruz Villalón, «Crisis económica y reformas de la legislación laboral en España», Ponencia en el EUROPEAN REGIONAL CONGRESS XI: DUBLIN (IRELAND), 17-19 SEPTEMBER 2014, de la Sociedad Internacional de Derecho del Trabajo y de la Seguridad Social. Disponible en internet: http://islssl.org/wp-content/uploads/2014/10/RoundTable2-Spain-JesusCruzVillalon.pdf 
determinante. El resultado es un debilitamiento del «poder» sindical, del trabajo que es ahora incapaz de codeterminar la salida al conflicto distributivo. La nueva flexibilización del despido, facilitándolos en mayor medida, hace que el trabajo se convierta exclusivamente en un factor de gestión del beneficio empresarial. La flexibilidad interna, posibilitando una adaptación, podríamos decir extrema, de las condiciones de trabajo a las exigencias de gestión empresarial, desprotege a los trabajadores que solo en los espacios reducidos de presencia sindical importante conservan una lógica colectiva de la definición de las condiciones de trabajo, provocando una reindividualización que agudiza su debilidad.

En definitiva, se produce una inversión de la intervención normativa en el trabajo que, frente a la lógica promocional que permitía fortalecer su capacidad negocial, expulsa al trabajo del sistema, lo hace, sin embargo mediante instrumentos infraconstitucionales y de emergencia que expresan las técnicas de influencia del ordenamiento europeo en el corazón de nuestro sistema constitucional. No se olvide que la reforma del mercado de trabajo, junto con la de las pensiones, son las que simbolizan las reformas estructurales.

Frente a esta forma de desconstitucionalización de los contenidos del Estado social el Tribunal constitucional responde con una ejemplificación de eufemismo del dialogo de jurisdicciones. La banalización de la negociación colectiva, desconectándola del Estado social y la intervención promocional del trabajo que realiza la mayoría del Tribunal en la sentencia 119/2014 es ejemplo del carácter disciplinante del ordenamiento de la UE. La contraposición entre constitución y reforma laboral viene reconocida por parte de algunos integrantes del tribunal (véanse el voto particular de F. Valdes Dal-Re al que se adhieren A. Asua Batarrita y L. I. Ortega Alvarez), que abre un flanco evidente a la crítica jurídica de la sentencia.

Una ultima consideración sobre la intervención normativa regresiva en la tutela del trabajo. Se refiere a la garantía de los instrumentos de autotutela del trabajo, vinculado con la subjetivización política y social que operaba el Estado social. Un programa de equilibrio de las partes en la constitucionalización del conflicto. La trascendencia de esta intervención y su constitucionalización caracterizan el estado social «La intangibilidad de las condiciones constitutivas de los sujetos fundamentales del conflicto económico-social: iniciativa económica privada y libertad sindical» ${ }^{85}$, es uno de los elementos fundamentales de la constitución material del Estado social. La huelga se vincula directamente con la libertad sindical y con el reconocimiento del trabajo como sujeto del conflicto social constitucionalizado. Desde esta perspectiva, resulta especialmente trascen-

85 P. Barcelona y A. Cantaro, La sinistra e lo Stato sociale, op. cit. pp. 46. 
dente la criminalización de la huelga que la reforma del código penal realiza en la ley orgánica 1/2015. El nuevo artículo 315.3, penalizando las coacciones a iniciar o continuar una huelga con penas de indudable gravedad (de 1 año y 9 meses a 3 años) supone un desincentivo a la participación en la huelga que limita el uso de un instrumento de autotutela imprescindible ${ }^{86}$. La huelga es un derecho de conflicto social ${ }^{87}$ como tal incorpora inevitablemente una tensión que se acentúa en los momentos de crisis, introducir mecanismos de disciplina que dificulten su ejercicio es contrario al modelo de huelga que constitucionaliza el estado social (ver la STC 11/1981).

\section{LA FORMA GLOBAL DE MERCADO Y LA DESCONSTITUCIONALIZACIÓN DEL ESTADO SOCIAL}

Aunque, como hemos dicho, la pérdida de los caracteres que definían el paradigma constitucional configurado en la experiencia del constitucionalismo de las II. ${ }^{a}$ postguerra mundial se produce normativamente y jurídicamente mediante su absorción por el ordenamiento de la UE, este actúa en el contexto global que impone la Forma Global de Mercado como nueva forma emergente que rompe con el Estado social. Porque la UE es la forma de inserción de Europa en el contexto global, más evidentemente desde la instauración de la UEM que interioriza los principios del nuevo orden como núcleo de su actuación, homogeneizan con ellos los ordenamientos de los Estados miembros.

No es el momento de caracterizar la Forma Global de Mercado ${ }^{88}$, solo cabe mencionar que esta se define por contraposición al Estado social e incorpora un programa opuesto, en abierta contradicción. Supone, su afirmación, la ruptura de la forma de Estado anterior.

También asume las transformaciones que impone la generalización del mercado respecto al espacio estatal, donde se incluye éste, redefiniendo sus funciones en una relación de subordinación.

El programa de la Forma Global de Mercado reconocible en las reflexiones realizadas respecto al proceso de desconstitucionalización del Estado social

86 J. M. Paredes Castañón (2014), «Represión penal del derecho de huelga. Una interpretación restrictiva del código penal», en Fundación $1 .^{\circ}$ de mayo, colección estudios, n. ${ }^{\circ} 103 ; \mathrm{C}$. H. Preciado Domenech, «Represión penal de la huelga. La vuelta a la España del siglo XIX», en Sin Permiso, 20/07/2014.

${ }^{87}$ G. Maestro Buelga, Derechos de conflicto social y participación politica en la Unión europea, op. cit.

${ }^{88}$ Me remito a mi trabajo Del Estado social a la Forma Global de Mercado, op. cit. 
podríamos sintetizarlas de esta manera: El marco general, frente al programa del Estado social: la integración del trabajo, es precisamente la expulsión del trabajo del sistema. Lo hace mediante la mercantilización del conflicto distributivo. Este impone el rechazo a las formas de integración económica del Estado social: El vínculo social al mercado, los instrumentos de intervención ligados al éste, los derechos sociales como forma de integración a través del Estado, la promoción del trabajo como sujeto del conflicto constitucionalizado.

Este programa afecta a los elementos constitutivos del Estado social y necesariamente implica su devaluación, privándoles de su dimensión constitucional. La Constitución, respecto a los contenidos vinculados a la forma de Estado que constitucionaliza, pierde su fuerza normativa, incapaz de disciplinar el ordenamiento jurídico que viene determinado por los caracteres de la Forma Global de Mercado.

¿Que queda del Estado social de la Constitución de 1978? Podríamos decir que, paradójicamente, una dimensión legitimadora asentada en el simbolismo retórico lingüístico de nuestro texto constitucional. Pero vacío de contenido.

Title:

The Welfare State 40 years later: The deconstitutionalization of the constitutional programme

Summary:

1. Introduction 2. The meaning of the welfare state clause in the Spanish Constitution of 1978. 3. The rupture in the way social status. 4 . The global form of market and the deconstitucionalization of the welfare state.

\section{Resumen:}

El trabajo analiza las tensiones entre los elementos propios del Estado social insertos en las diversas constituciones de los Estados europeos y los condicionantes económicos impuestos por la Unión europea, especialmente en los últimos años de crisis económica. Uno de los ejemplos estudiados es el de la constitucionalización del principio de estabilidad presupuestaria. Se sostiene en el texto que se ha «desconstitucionalizado» el estado social en España, como consecuencia 
de estas reformas acometidas en los años de la crisis económica, de manera que se han vaciado de contenido las cláusulas del Estado social previstas en nuestra Constitución.

\section{Astract:}

The paper analyzes tensions between elements of the Welfare State inserts in the various constitutions of the European States and the economic conditions imposed by the European Union, especially in the last years of economic crisis. One of the studied examples is the constitutionalization of the principle of budgetary stability. It says in the text that it has «deconstitutionalized» the Welfare State in Spain, as a result of these reforms undertaken in the years of the economic crisis, so have emptied of content clauses of the Welfare State provided for in our Constitution.

\section{Palabras clave:}

Estado Social, Constitución española, Unión Europea, Reformas económicas, Mercado laboral, Unión económica y Monetaria.

\section{Key words:}

Welfare State, Spanish Constitution, European Union, economic reforms, labour market, Economic and monetary Union. 